\title{
CADEIA PRODUTIVA DA NÊSPERA NA REGIÃO DO ALTO TIETÊ: INDICADORES ECONÔMICOS DA PRODUÇÃO E MERCADO ATACADISTA ${ }^{1}$
}

\author{
JOSÉ MATHEUS YALENTI PEROSA², EMERSON MORAIS VIEIRA ${ }^{3}$, THOMAS NITZSCHE $^{4}$
}

\begin{abstract}
RESUMO - A região do Alto Tietê é responsável por 85\% da produção de nêspera do Estado de São Paulo. Atividade rentável, nos últimos anos os produtores verificaram uma queda na sua lucratividade. Este trabalho teve como objetivos sistematizar informações econômicas sobre a cadeia produtiva e analisar a estrutura de mercado. A evolução dos preços da nêspera mostra crescimento até o ano 2000 e posterior queda. O mercado atacadista tem atuado como um "colchão" amortecedor. O maior desafio para os produtores de nêspera se encontra no âmbito organizacional. A estrutura de mercado e os resultados da pesquisa de campo indicam que os produtores do Alto Tietê encontram-se em posição vantajosa para um reposicionamento nesse aspecto, importante para uma participação sustentável na atividade.
\end{abstract}

Termos para indexação: nêspera; cadeia produtiva; rentabilidade.

\section{MEDLAR PRODUCTIVE CHAIN IN HIGH TIETÊ REGION: ECONOMIC INDICATORS OF PRODUCTION AND WHOLESALER MARKET}

ABSTRACT - High Tietê region is responsible for $85 \%$ of medlar production in São Paulo State. Profitable activity, in the last years producers have verified a decrease in its profitability. The aims of this study were to systemize economic information on the productive chain; to analyze the market structure and to simulate offer displacement economic viability. Medlar prices increase shows a growth until the year 2000 and a posterior decrease. The wholesale market has acted as a "cushioning mattress". Market structure and this study results showed that producers are in an advantageous position for a change, important to a sustainable participation in the activity.

Index terms: medlar; productive chain; profitability.

\section{INTRODUÇÃO}

A região do Alto Tietê, composta pelos municípios de Mogi das Cruzes, Guararema, Biritiba-Mirim, Salesópolis e Santa Isabel, é uma das mais importantes do País na produção de hortifrutícolas. Dessa região, saem diariamente 1.255 toneladas de hortifrutigranjeiros e flores, abastecendo $35 \%$ do mercado consumidor de SP (55\% do volume destes produtos no CEAGESP) e 5\% do Rio de Janeiro. (Sindicato Rural de Mogi das Cruzes, 2000).

A região possui 3.500 produtores, sendo $75 \%$ constituídos de pequenos produtores (até $05 \mathrm{ha}$ ), 20\% de médios e 5\% de grandes produtores. (CATI-EDR, Mogi das Cruzes).

A fruticultura apresenta como principais espécies a nêspera e o caqui, com 180 produtores ocupando 2.134 ha (1.884 ha de caqui e 250 ha de nêspera). A região é responsável por $85 \%$ da produção de nêspera no Estado, com um volume anual de 800 toneladas. (Sindicato Rural de Mogi das Cruzes, 2000).

A nêspera (Eriobotya japonica), também chamada de ameixaamarela, é uma planta oriunda do Japão e China, tendo sido aclimatada no Brasil pelos colonos japoneses que aqui vieram como imigrantes. Ao longo do tempo, a produção de nêspera desenvolveu-se na região do Alto Tietê, apresentando como característica importante a de ser complementar à cultura do caqui.

Em trabalhos desenvolvidos junto a produtores da região e técnicos ligados ao setor, constatou-se a percepção dos mesmos de uma queda na rentabilidade da atividade.

O presente estudo teve como objetivo analisar parâmetros quantitativos e qualitativos da cadeia produtiva da nêspera e resultados econômicos obtidos, como subsídio de análise ao comportamento de mercado nessa atividade econômica.

\section{MATERIAL E MÉTODOS}

O conceito de competitividade abriga ampla diversidade nos métodos de abordagem e parâmetros determinantes.
FAJNZYLBER (1988) desenvolve um conceito amplo do termo competitividade, denominando-o "competitividade estrutural". Neste caso, assume-se a existência de diversos fatores que exercem competência nos mercados atuais, não necessariamente ligados aos preços (ou aos custos), tais como: atividades de $\mathrm{P} \& \mathrm{D}$, qualidade e diferenciação do produto, eficiência e organização dos sistemas produtivo e comercial, controles de qualidade, etc.

Vários estudos (ALONSO, 1992; PEROSA, 1999; SANTIAGO, 2001 e SATO, 2002) apontam que a estrutura de mercado tem papel importante na conduta dos agentes econômicos no âmbito de um segmento da cadeia. Como resultado desse pressuposto, a política de preços a teria como determinante, configurando-se como parâmetro de referência para o próprio mecanismo de formação dos preços. Nesse sentido, o desempenho dos agentes econômicos e sua eficiência, seriam influenciados pela estrutura dos mercados.

Por outro lado, a competitividade extrapola relações horizontais entre os agentes econômicos para uma articulação vertical ao longo da cadeia. A identificação de pontos críticos não pode ser focada de forma isolada, setorial, mas através de uma visão sistêmica, onde o levantamento de informações deve contemplar a mútua influência exercida pelos segmentos que a compõem.(vide BATALHA, 1997; SEBRAE, 2000 e SILVA, 1999).

Com essa perspectiva, o procedimento para o levantamento de informações sobre a cadeia produtiva da nêspera foi orientado para a coleta de dados a campo, sistematizados em diferentes aspectos relativos aos segmentos da cadeia produtiva. Procurou-se captar, nas entrevistas, as relações horizontais (tais como de ações coletivas entre os produtores), e as verticais, resultado das características das transações econômicas dos produtores e mercado atacadista. Tais relações constituíram suporte para a análise da estrutura de mercado e comportamento dos preços.

Para a coleta de preços e custos na esfera da produção, foram efetuadas entrevistas com produtores representativos na região estudada e também com técnicos de notório conhecimento na área. A série temporal de preços de mercado e sua evolução foram coletados

\footnotetext{
${ }^{1}$ (Trabalho 034-2006). Recebido: 21-03-2006. Aceito para publicação: 08-06-2006.

2 Depto de Gestão e Tecnologia Agroindustrial - Fac. de Ciências Agronômicas - Campus de Botucatu - UNESP - Faz. Exp. Lageado - Cx. P. 237 - 18603970 - Botucatu - SP e-mail: dede@ fca.unesp.br.

${ }^{3}$ Eng. Agrônomo, Consultor SEBRAE/SP - E.R. Mogi das Cruzes e-mail: emrsonv@ @sebraesp.com.br.

${ }^{4}$ Eng. Agrônomo - Sindicato Rural de Mogi das Cruzes e Pesquisador do Instituto para o Desenvolvimento de Agronegócios - IDEAGRO e-mail: thomasnitz@uol.com.br.
} 
junto à CEAGESP e Instituto de Economia Agrícola - IEA / SAA-SP.

Para a atualização dos preços, utilizou-se como índice o IGPDI, calculado pela Fundação Getúlio Vargas. Para o cálculo dos índices de variação estacional de preços e quantidade ofertada, foi utilizado o método da média geométrica móvel centralizada.

O levantamento de informações e a sistematização dos problemas nas esferas da produção e comercialização foram realizados por técnicos do Sindicato Rural de Mogi das Cruzes, do SEBRAE-SP e da CATI. Foi analisado um grupo-padrão formado por 30 produtores de nêspera e caqui, de forma complementar, organizados numa associação denominada Associação Frutícola do Alto Tietê - AFRUT.

\section{RESULTADOS E DISCUSSÃO}

\section{Aspectos da produção e comercialização de nêspera.}

Na identificação dos pontos críticos na esfera da produção, algumas características foram destacadas. Os principais problemas detectados foram agrupados em 03 aspectos principais: tecnológico, mercadológico e de infra-estrutura.

- Aspectos de Produção e Tecnológicos: deficiência da orientação agronômica, técnicas de produção e pós-colheita que necessitam de aprimoramento tecnológico e mão-de-obra desqualificada, ocasionam como principais problemas: aumento do percentual de produtos com classificação inferior, perdas no processo de colheita, classificação, embalagem e transporte. O custo de produção é elevado, relacionado principalmente ao ensacamento do fruto nos pés e à colheita; o produto é altamente perecível e sensível a choques mecânicos. A nêspera apresenta também grande instabilidade na produção, sendo extremamente sensível a variações climáticas.

- Aspectos Mercadológicos: sistema de comercialização inadequado, onde o consumidor não conhece a fruta (suas diferentes variedades, forma de consumo, sazonalidade e qualidade); alta inadimplência (os contratos são informais, históricos, baseados na confiança, e os produtos, em sua maioria, são entregues em consignação); prazo de recebimento muito longo.

- Aspectos de Infra-estrutura: precárias condições das estradas rurais, ausência de entrepostos locais para escoamento do produto (logística) e equipamentos inadequados para o transporte da fruta, não havendo investimentos no sistema de comercialização a frio, sendo que, no CEAGESP, os atacadistas não tinham como armazenar os frutos em câmaras frias e tampouco os varejistas possuíam plataformas para o recebimento deste tipo de produto.

Especificamente na esfera da comercialização, um diagnóstico resumido das principais situações encontradas foram listadas:

- A comercialização da fruta é baseada no mercado spot, centralizado na CEAGESP;

- Embora haja grande concentração da produção na região, a formação de preços é fortemente influenciada por poucos atacadistas, sem qualquer transparência dos critérios utilizados para os produtores;

- Até o ano 2000, as embalagens não eram padronizadas e praticamente todos enviavam em caixas de madeira: a partir de então, passam a ser utilizados outros tipos de embalagens;

- Desconhecimento dos produtores sobre o destino de seus produtos. Quando entregue aos atacadistas, davam por encerrado seu papel e, portanto, não conheciam o mercado consumidor;

- Ausência do uso de ferramentas de gestão, tais como a apropriação de custos de produção e comercialização, e parâmetros de competitividade.

Praticamente não há regiões produtoras concorrentes, e o número de produtores é relativamente pequeno, embora não o seja quando comparado com a estrutura do mercado atacadista.

Em conjunto, estes fatores apontam para uma desarticulação e desorganização do setor, ausência de planejamento a curto, médio e longo prazos, e conduta caracterizada por ações individualistas, buscando vantagens imediatas e desalinhadas estrategicamente. Nesse cenário, abre-se espaço para a ocorrência de condutas que podem influenciar na perda de competitividade da cadeia, como a não-adequação a demandas de mercado e apropriação de maiores margens pela concorrência de outras frutas.

\section{Comportamento dos preços}

O mercado de hortifrutícolas é fortemente influenciado por parâmetros quantitativos da oferta e procura. A apropriação das margens decorrentes das variações de preços é fortemente influenciada pela estrutura de mercado nos seus diversos níveis. Embora haja possibilidade para manipulação dos preços em nível de atacado, os determinantes para sua formação estão fortemente vinculados à quantidade ofertada vis-a-vis a procura. É o caso do mercado de nêspera, onde a variação de preços tem uma relação direta com a quantidade ofertada.

A Figura 1 mostra a evolução dos índices de preços e quantidade ofertada na CEAGESP, no período de 1998-2004. Os dados refletem a média anual dos meses de safra, entre junho e dezembro. Observa-se uma forte queda na quantidade ofertada nos anos de 2000 e 2004, ambas decorrentes de problemas climáticos. Em 2000, o alto índice de umidade verificado ocasionou o aparecimento de doenças, com apodrecimento interno dos frutos. Em 2004, a falta de chuvas no período que antecede a frutificação, foi a responsável pela queda na produção. Os preços foram atualizados em valores de dezembro de 2004 e transformados em índices, tendo como ano-base 1998.

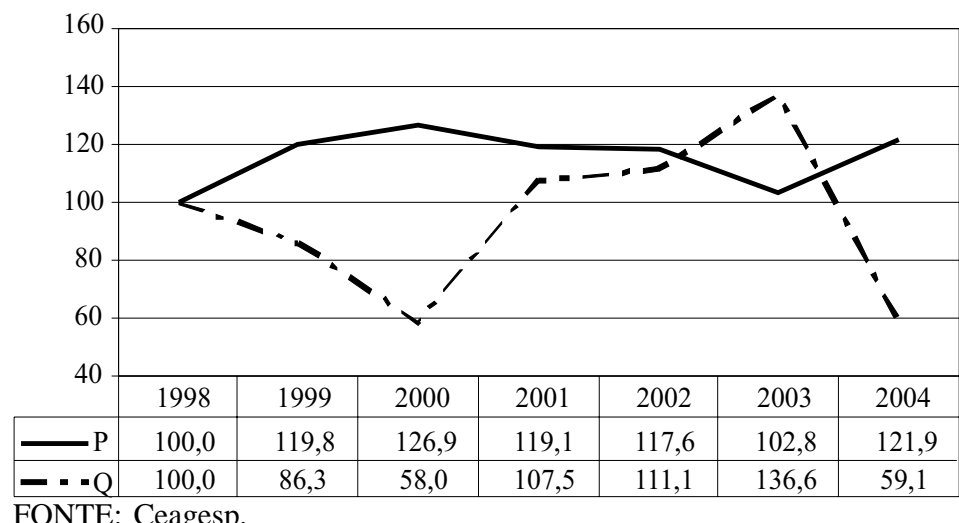

FIGURA 1 - Evolução dos índices de preço e quantidade ofertada no atacado - CEAGESP - Período 1998-2004 - 1998=100.

No período considerado, observa-se uma correspondência inversa entre preço e quantidade ofertada. Essa mesma relação se observa no mercado primário. A distribuição da oferta de nêspera durante o ano é bastante concentrada nos meses de safra, de agosto a novembro, com $82 \%$ do total produzido (Figura 2).

Da mesma forma que no atacado, observa-se uma relação inversa durante o ano entre o preço recebido e a produção na região de Mogi das Cruzes (Figura 3).

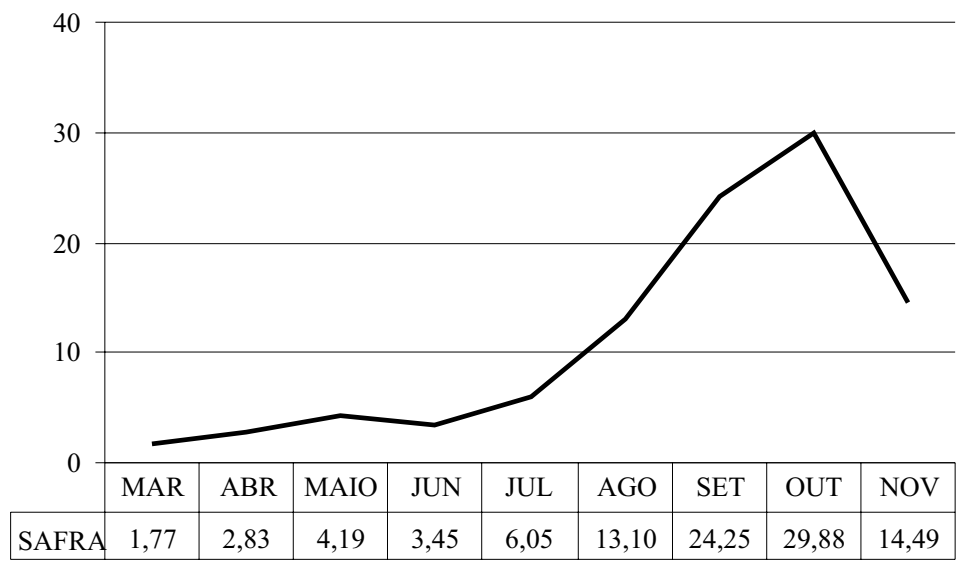

FONTE: Sindicato Rural de Mogi das Cruzes - AFRUT, 2000.

FIGURA 2 - Concentração da safra de nêspera ao longo do ano - \% 


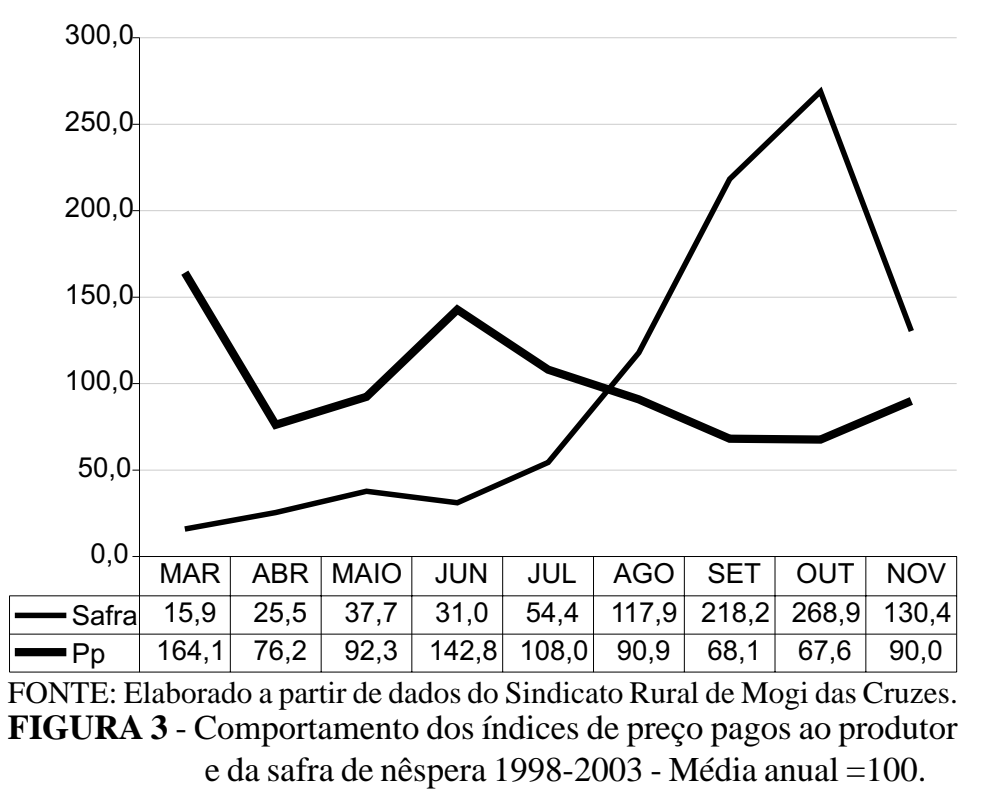

Comparando o comportamento dos preços médios mensais no período de safra, referente aos anos de 1998-2003, observa-se um comportamento diferenciado entre os mercados primário e atacadista, com variações mais pronunciadas nos preços pagos aos produtores (Figura 4).

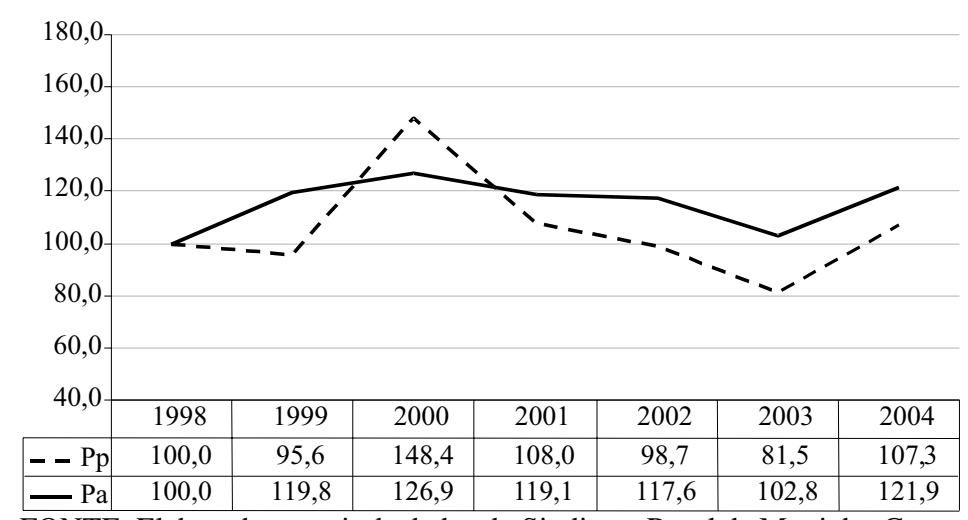

FONTE: Elaborado a partir de dados do Sindicato Rural de Mogi das Cruzes e Ceagesp.

FIGURA 4 - Evolução dos índices de preço pagos ao produtor e do atacado de nêspera 1998-2004 1998=100

A evolução dos preços reais pagos ao produtor, a partir de 1998 , tem um comportamento crescente até o ano 2000 e posterior queda até 2003, quando se observa uma recuperação em patamar próximo a 1998. No atacado, também ocorre um comportamento similar: a diferença é que essa evolução se verifica de forma menos acentuada, atuando o atacado como um "colchão amortecedor" para cima e para baixo. O crescimento dos preços mais pronunciado no ano 2000 está relacionado com uma quebra de safra verificada (vide Figura 1). Os anos posteriores mostram uma recuperação da oferta, e uma queda mais pronunciada dos preços recebidos pelo produtor.

\section{CONCLUSÕES}

1) Os preços pagos ao produtor se encontravam em patamares elevados nas décadas de 80 e 90 . Esse comportamento propiciou uma alta lucratividade no setor. Dada a concorrência com outras frutas e aumento da quantidade ofertada, era esperada uma redução dos preços e da lucratividade.

2) A mobilização dos produtores da AFRUT frente a essa perspectiva implementou ações preventivas, com um trabalho de padronização e embalagem já em 1999. Resultado dessa ação foi o estabelecimento de uma caixa de embalagem-padrão e, também, como estratégia de marketing, todas as caixas teriam o mesmo lay-out, vendendo um produto made in Mogi das Cruzes. Em 2000, estenderam a padronização para quase a totalidade da produção.

3) Neste ano, houve um acréscimo de cerca de $50 \%$ no preço recebido por kg devido a uma quebra de safra de $30 \%$, o que propiciou aos produtores a oportunidade de venda a melhores preços que no ano anterior.

4) Essas ações preventivas não conseguiram segurar a queda na lucratividade, com redução maior dos preços pagos ao produtor em relação ao atacado, nos anos de 2001-2003, quando da recuperação da oferta.

5) Importante ressaltar que tais ações induzem a um aumento nos custos de produção e de comercialização. Houve agregação de valor ao produto, mas os benefícios dessa estratégia não foram apropriados pelos produtores.

6) Para a cadeia como um todo, estratégias conjuntas entre os agentes da cadeia são fundamentais para a oferta de um produto competitivo e focado na estrutura da demanda.

7) As informações levantadas de mercado indicam que o elemento custo não é o fator preponderante na formação do preço pago ao produtor. A desarticulação da cadeia faz com que os atacadistas possuam uma posição vantajosa, onde conseguem concentrar produção e informação. Tal vantagem é frágil ao longo do tempo, pois implica movimentos à jusante e montante de organização e de novos reposicionamentos estratégicos.

8) O maior desafio para os produtores de nêspera se encontra no âmbito organizacional. Os resultados de ações coletivas já desenvolvidas pelos produtores constituem parâmetro importante para novas ações nessa área. A estrutura de mercado e os resultados da pesquisa de campo indicam que os produtores do Alto Tietê se encontram em posição vantajosa para um reposicionamento.

9) As perspectivas de uma melhoria na competitividade da cadeia produtiva da nêspera são promissoras. Entre ações que podem ser implementadas e/ou aprimoradas, relacionadas ao incremanto de marketing e as direcionadas à melhoria da oferta, destacam-se:

- Melhoria das técnicas de pós-colheita, como no caso de câmaras frias, podendo contribuir no futuro para alongar o prazo de oferta e manter um preço mais estável ao longo do ciclo da produção;

- Incremento nas ações de marketing, como campanhas de lançamento de safra e de degustação, fortalecimento da logomarca regional, exposição do produto na mídia, gôndolas especiais nos centros consumidores, etc.;

- Rastreabilidade do produto, estabelecendo uma rota de informação desde o produtor até o consumidor;

- Intensificação das atividades associativistas.

10) Ações como as listadas estariam a compor um planejamento estratégico de médio e longo prazos visando a criar condições competitivas sustentáveis na cadeia, ao mesmo tempo propiciando margens atraentes para investimentos na esfera da produção e comercialização.

11) Finalizando, as informações e dados apresentados caracterizam o produto como tomador de preços, sendo necessário ações visando a redução de custos na esfera da produção.

\section{REFERÊNCIAS}

ALONSO, J. A., Ventajas comerciales y competitividad: aspectos conceptuales y empíricos. Información Comercial Española, Madrid, n.705, p-3876, 1992.

BATALHA, M.O. (Coord.). Gestão agroindustrial. São Paulo: Editora Atlas, 1997.573p.

CATI - Coordenadoria de Assistência Técnica Integral.Título. Disponível em: <http://www.cati.sp.gov.br>. Acesso em: 13 jan. 2006. 
FAJNZYLBER, F. Competitividad intenacional: evolucion y lecciones. Revista de la Cepal, Santiago, n. 36, p.7-24, 1988.

Instituto de Economia Agrícola. Título. São Paulo: Secretaria de Agricultura e Abastecimento de São Paulo. Disponível em: <http:/ /www.iea.sp.gov.br>. Acesso em: 17 jan. 2006.

PEROSA, J.M.Y.; MOREIRA, M.S.T.E. Diagnóstico econômico de agronegócios no Estado de São Paulo: a cadeia do cogumelo. Botucatu: SEBRAE-FEPAF, 1999. 87 p. Relatório de Pesquisa.

SANTIAGO, M.M.D.; ROCHA, M.B. - O mercado de frutas e as estimativas dos preços recebidos pelos fruticultores no Estado de São Paulo 1990-2000. Informações Econômicas-São Paulo, v.31, n.2, 2001.
SATO, G.S.; ASSUMPÇÃO, R. Mapeamento e análise da produção do caqui no Estado de São Paulo. Informações Econômicas-São Paulo, v.32, n.6, 2002.

SEBRAE, Metodologia do Programa SEBRAE: cadeias produtivas agroindustriais. Brasília: SEBRAE/CNA, 2000.

SILVA, C.A.B.; BATALHA, M. Competitividade em Sistemas Agroindustriais: Metodologia e Estudo de Caso. In: WORKSHOP BRASILEIRO SOBRE GESTÃO DE SISTEMAS AGROINDUSTRIAIS, 2., 1999, Ribeirão Preto. Anais... Ribeirão Preto: FGA/USP, 1999.

SINDICATO RURAL DE MOGI DAS CRUZES. Perfil da agricultura de Mogi das Cruzes. 2000. 22p. mimeo. 